\title{
Absolute Configuration of (-)-Cubebin, a Classical Lignan with Pharmacological Potential, Defined by Means of Chiroptical Spectroscopy
}

\author{
Arthur L. Macedo, ${ }^{\circledR \#, a}$ Lucas H. Martorano, ${ }^{\circledR \#, b}$ Ana Carolina F. de Albuquerque, ${ }^{b}$ \\ Rodolfo G. Fiorot, ${ }^{\oplus *, b}$ José W. M. Carneiro, ${ }^{\circledR c}{ }^{c}$ Vinicius R. Campos, ${ }^{\circledR b}$ \\ Thatyana R. A. Vasconcelos, ${ }^{\oplus b}$ Alessandra L. Valverde, ${ }^{\oplus b}$ Davyson L. Moreira ${ }^{\circledR d}$ \\ and Fernando M. dos Santos Jr. ${ }^{\circledR *, b}$ \\ ${ }^{a}$ Faculdade de Ciências Farmacêuticas, Alimentos e Nutrição, \\ Universidade Federal do Mato Grosso do Sul, 79070-900 Campo Grande-MS, Brazil \\ ${ }^{b}$ Departamento de Química Orgânica, Instituto de Química, \\ Universidade Federal Fluminense, 24020-141 Niterói-RJ, Brazil \\ 'Departamento de Química Inorgânica, Instituto de Química, \\ Universidade Federal Fluminense, 24020-141 Niterói-RJ, Brazil \\ ${ }^{d}$ Departamento de Produtos Naturais, Farmanguinhos, \\ Fundação Oswaldo Cruz, 21040-360 Rio de Janeiro-RJ, Brazil
}

\begin{abstract}
This work describes the first determination of the absolute configuration (AC) of (-)-cubebin by means of electronic circular dichroism (ECD), supported by quantum chemical calculations. The comparison of experimental ECD with the corresponding quantum chemical prediction for the proper diastereoisomer resulted in the definitive assignment of the $\mathrm{AC}$ of the naturally occurring (-)-cubebin as $(8 R, 8 \mathrm{a} R, 9 S)$. The challenging determination of the relative configuration (RC) of cubebin based only on experimental nuclear magnetic resonance (NMR) methods is stressed. Computation of the ${ }^{13} \mathrm{C}$ and ${ }^{1} \mathrm{H}$ NMR chemical shifts for all the possible diastereoisomers leads to values of mean absolute error and root mean square deviation that do not allow distinguishing among them. Thus, errors in stereochemical determination can easily occur even when using twodimensional methods, which clearly demonstrate the complexity of this special case. To determine the RC of this bioactive natural compound with high level of confidence, it was necessary to combine the DP4+ method with X-ray crystallography. Therefore, employing the commonly used empirical methods to determine the AC of (-)-cubebin can easily lead to misassignment of its stereochemistry.
\end{abstract}

Keywords: cubebin, absolute configuration, NMR simulation, X-ray crystallography, ECD

\section{Introduction}

(-)-Cubebin is a bioactive natural dibenzylbutyrolactolic lignan found in several species of plants, especially in the genus Piper. ${ }^{1,2}$ Although this compound has been known for 150 years by now, its numerous biological properties, such as analgesic, anti-inflammatory, antimicrobial, antihistaminic, vasodilator and cytotoxicity on tumor cells, have attracted the attention of several research groups all over the world. ${ }^{2}$ Recent research ${ }^{2}$ with cubebin has

*e-mail: rodolfofiorot@id.uff.br; fernando_martins@id.uff.br

\#These authors contributed equally to this work. focused on the discovery of new biological properties and in obtaining semisynthetic derivatives to potentiate their pharmacological properties.

Due to its promising therapeutic effects on schistosomiasis and Chagas disease, cubebin became extremely important as a potential new drug, justifying the great chemical and pharmacological interest. ${ }^{2} \mathrm{We}$ recently reported ${ }^{3}$ the promising cytotoxic activity of a dichloromethane fraction of the methanolic extract from leaves of Piper cernuum Vell. In that previous work, Macedo et al. ${ }^{3}$ found one of the stereoisomers of cubebin (Figure 1) as the major component in the bioactive fraction. 
<smiles>O[C@@H]1OC[C@H](Cc2ccc3c(c2)OCO3)[C@H]1Cc1ccc2c(c1)OCO2</smiles><smiles>O[C@@H]1OC[C@H](Cc2ccc3c(c2)OCO3)[C@H]1Cc1ccc2c(c1)OCO2</smiles>

Figure 1. Four possible diastereoisomers of cubebin.

Despite of its relatively simple structure, cubebin presents 3 stereogenic centers. Several authors ${ }^{4-8}$ have shown that its configuration are intrinsically related to the wide range of biological activities. In 2006, de Pascoli et al. ${ }^{9}$ proposed an absolute configuration (AC) for cubebin based on chemical transformations. The hydroxyl group in cubebin was oxidized, transforming it into hinokinin, with the AC well established. ${ }^{9}$ However, even using the chemical transformations, the configuration of the anomeric center in cubebin remains unclear, as seen in other butyrolactolic lignans. ${ }^{9-12}$ Additionally, the use of correlations or spectral comparison with compounds of known $\mathrm{AC}$, usually does not yield reliable results regarding the absolute configuration. ${ }^{13}$ In this particular case, empirical methodologies such as chemical transformations can easily lead to misassignment, since the electronic circular dichroism (ECD) spectrum of different diastereoisomers of cubebin could show similar bands. ${ }^{9}$ Thus, revisiting the configuration of cubebin using a more reliable stereochemical method is highly recommended.

Nowadays, the combination of nuclear magnetic resonance (NMR), one of the most powerful techniques for relative configuration determination, with ECD, which explores the electronic properties of the molecules, both associated with high level quantum chemical calculations, is considered the best approach for reliable stereochemical assignments of natural products. ${ }^{13-17}$ Thus, aiming the full identification of the compound present in the P. cernuum cytotoxic fraction, ${ }^{3}$ we report the isolation and the first analysis of the stereostructure of naturally occurring cubebin by means of NMR and ECD, both supported by their corresponding quantum chemical prediction.

\section{Results and Discussion}

The isolated compound was obtained as a white amorphous solid, whose molecular formula was suggested as $\mathrm{C}_{20} \mathrm{H}_{20} \mathrm{O}_{6}$ based on $[\mathrm{M}]^{+} \mathrm{m} / 2356$ by gas chromatographymass spectrometry (GC-MS). The ${ }^{1} \mathrm{H}$ and ${ }^{13} \mathrm{C}$ NMR were similar to those reported for cubebin (Table 1). ${ }^{9}$ The ${ }^{13} \mathrm{C}$ NMR spectrum indicated 20 carbons and the ${ }^{1} \mathrm{H}$ NMR<smiles>O[C@@H]1OC[C@H](Cc2ccc3c(c2)OCO3)[C@H]1Cc1ccc2c(c1)OCO2</smiles>

showed signals that were attributed to the aromatic hydrogens $(\delta 6.66,6.55,6.49,6.65,6.51$ and 6.44$)$, two methylenedioxy groups $(\delta 5.83)$, two methynic hydrogens $(\delta 1.94$ and 1.83), two methylenic hydrogens $(\delta 2.46,2.30$ and 2.39), and one anomeric hydrogen $(\delta 4.90)$. The 2D spectral data of HSQC (heteronuclear single quantum coherence) and HMBC (heteronuclear multiple bond correlation spectroscopy) allowed the full assignment of the cubebin basic structure.

Mass spectrometry and NMR spectroscopy data suggested that the compound has a structure compatible

Table 1. ${ }^{1} \mathrm{H}$ and ${ }^{13} \mathrm{C}$ NMR data of the isolated cubebin

\begin{tabular}{|c|c|c|}
\hline Atom number & $\begin{array}{c}\delta^{13} \mathrm{C} / \mathrm{ppm} \\
\left(125 \mathrm{MHz}, \text { DMSO- } d_{6}\right)\end{array}$ & $\begin{array}{c}\delta{ }^{1} \mathrm{H} \text { (multiplicity, } J / \mathrm{Hz}, \\
\text { integral) / ppm } \\
\left(500 \mathrm{MHz}, \mathrm{DMSO}-d_{6}\right)\end{array}$ \\
\hline 1 & 134.3 & - \\
\hline 2 & 109.5 & $6.55(\mathrm{~d}, 1.6,1 \mathrm{H})$ \\
\hline 3 & 147.5 & - \\
\hline 4 & 145.7 & - \\
\hline 5 & 108.4 & $6.66(\mathrm{~d}, 7.6,1 \mathrm{H})$ \\
\hline 6 & 122.1 & $6.49(\mathrm{dd}, 7.9,1.7,1 \mathrm{H})$ \\
\hline 7 & 38.0 & $\begin{array}{l}2.46(\mathrm{dd}, 13.8,7.9,1 \mathrm{H}) \\
2.30(\mathrm{dd}, 13.6,7.5,1 \mathrm{H})\end{array}$ \\
\hline 8 & 53.4 & $1.83(\mathrm{~m}, 1 \mathrm{H})$ \\
\hline 9 & 102.9 & $4.90(\mathrm{~d}, 2.9,1 \mathrm{H})$ \\
\hline 1a & 134.8 & - \\
\hline $2 \mathrm{a}$ & 109.2 & $6.51(\mathrm{~d}, 1.7,1 \mathrm{H})$ \\
\hline $3 a$ & 147.6 & - \\
\hline $4 a$ & 145.7 & - \\
\hline $5 a$ & 108.3 & $6.65(\mathrm{~d}, 7.8,1 \mathrm{H})$ \\
\hline $6 \mathrm{a}$ & 121.7 & $6.44(\mathrm{dd}, 7.9,1.6,1 \mathrm{H})$ \\
\hline $7 \mathrm{a}$ & 38.7 & $2.39(\mathrm{~m}, 2 \mathrm{H})$ \\
\hline $8 \mathrm{a}$ & 45.9 & $1.94(\mathrm{~m}, 1 \mathrm{H})$ \\
\hline $9 \mathrm{a}$ & 71.0 & $\begin{array}{c}3.67(\mathrm{dd}, 8.3,7.6,1 \mathrm{H}) \\
3.47(\mathrm{t}, 8.2,1 \mathrm{H})\end{array}$ \\
\hline $\mathrm{OCH}_{2} \mathrm{O}$ & 101.0 & $5.83(\mathrm{~m}, 2 \mathrm{H})$ \\
\hline $\mathrm{OCH}_{2} \mathrm{O}$ & 101.0 & $5.83(\mathrm{~m}, 2 \mathrm{H})$ \\
\hline
\end{tabular}

$\delta$ : chemical shift values; $J$ : coupling constant; DMSO: dimethyl sulfoxide. 
with the lignan cubebin. Thus, we focused to determine the relative configuration for the three stereogenic centers present in the structure. The eight possible stereoisomers comprise four pairs of enantiomers. As each pair of enantiomers displays exactly the same NMR chemical shifts in isotropic media the first approach was to compute the ${ }^{13} \mathrm{C}$ and ${ }^{1} \mathrm{H}$ NMR chemical shifts for the four possible diastereoisomers of cubebin (see Figure 1) and compare them with those obtained experimentally for the isolated compound (Tables 2 and 3, respectively).

Table 2. Comparison of computed ${ }^{13} \mathrm{C}$ NMR chemical shifts $\left(\delta_{\text {scal }}\right)$ of the four possible diastereoisomers of cubebin with experimental data $\left(\delta_{\text {exp }}\right.$, $125 \mathrm{MHz}$, DMSO- $d_{6}$ ) for the corresponding isolated natural product

\begin{tabular}{|c|c|c|c|c|c|}
\hline \multirow{2}{*}{$\begin{array}{l}\text { Atom } \\
\text { number }\end{array}$} & \multicolumn{4}{|c|}{ Diastereoisomer $\delta_{\text {scal }}^{13} \mathrm{C} / \mathrm{ppm}$} & \multirow{2}{*}{$\begin{array}{c}\text { Isolated cubebin } \\
\delta_{\exp }{ }^{13} \mathrm{C} / \mathrm{ppm}\end{array}$} \\
\hline & 1 & 2 & 3 & 4 & \\
\hline 1 & 132.63 & 134.15 & 133.49 & 134.27 & 134.3 \\
\hline 2 & 110.40 & 109.59 & 109.29 & 109.38 & 109.5 \\
\hline 3 & 146.21 & 146.72 & 146.94 & 146.79 & 147.5 \\
\hline 4 & 144.59 & 144.93 & 145.07 & 144.99 & 145.7 \\
\hline 5 & 108.36 & 107.69 & 107.91 & 107.85 & 108.4 \\
\hline 6 & 121.86 & 122.05 & 122.03 & 121.97 & 122.1 \\
\hline 7 & 40.44 & 35.22 & 33.82 & 33.62 & 38.0 \\
\hline 8 & 52.16 & 54.48 & 51.29 & 51.82 & 53.4 \\
\hline 9 & 104.87 & 100.13 & 101.86 & 99.70 & 102.9 \\
\hline 1a & 132.96 & 133.32 & 133.52 & 134.67 & 134.8 \\
\hline $2 \mathrm{a}$ & 107.80 & 108.31 & 108.31 & 109.15 & 109.2 \\
\hline $3 \mathrm{a}$ & 146.59 & 147.25 & 147.17 & 146.95 & 147.6 \\
\hline $4 a$ & 144.89 & 145.33 & 145.20 & 144.96 & 145.7 \\
\hline $5 a$ & 106.87 & 107.92 & 108.00 & 107.91 & 108.3 \\
\hline $6 a$ & 122.35 & 121.25 & 121.06 & 122.03 & 121.7 \\
\hline $7 a$ & 42.80 & 40.72 & 36.40 & 38.87 & 38.7 \\
\hline $8 a$ & 43.06 & 44.71 & 42.91 & 44.23 & 45.9 \\
\hline $9 \mathrm{a}$ & 73.22 & 73.71 & 71.96 & 72.13 & 71.0 \\
\hline $\mathrm{OCH}_{2} \mathrm{O}$ & 101.87 & 102.14 & 102.31 & 102.27 & 101.0 \\
\hline $\mathrm{OCH}_{2} \mathrm{O}$ & 102.14 & 102.45 & 102.40 & 102.32 & 101.0 \\
\hline MAE & 1.46 & 1.08 & 1.15 & 0.96 & - \\
\hline RMSD & 1.72 & 1.38 & 1.52 & 1.44 & - \\
\hline
\end{tabular}

$\delta$ : chemical shift values; MAE: mean absolute error; RMSD: root mean square deviation.

Table 2 shows the comparison of the computed ${ }^{13} \mathrm{C}$ NMR chemical shifts shifts for the four diastereoisomers of cubebin with experimental data. Mean absolute errors (MAE) and root mean square deviations (RMSD) are also given. Although diastereoisomers $\mathbf{2}$ and $\mathbf{4}$ show the lowest ${ }^{13} \mathrm{C}$ NMR MAE and RMSD values, the differences for diastereoisomers $\mathbf{1}$ and $\mathbf{3}$ are small, not allowing for definitive determination of the relative configuration of
Table 3. Comparison of theoretical ${ }^{1} \mathrm{H}$ NMR chemical shifts $\left(\delta_{\text {scal }}\right)$ of the four diastereoisomers of cubebin with experimental data $\left(\delta_{\text {exp }}, 500 \mathrm{MHz}\right.$, DMSO- $d_{6}$ ) for the isolated natural product

\begin{tabular}{|c|c|c|c|c|c|}
\hline \multirow{2}{*}{$\begin{array}{l}\text { Atom } \\
\text { number }\end{array}$} & \multicolumn{4}{|c|}{ Diastereoisomer $\delta_{\text {scal }}{ }^{1} \mathrm{H} / \mathrm{ppm}$} & \multirow{2}{*}{$\begin{array}{c}\text { Isolated cubebin } \\
\delta_{\exp }{ }^{1} \mathrm{H} / \mathrm{ppm}\end{array}$} \\
\hline & 1 & 2 & 3 & 4 & \\
\hline 1 & - & - & - & - & - \\
\hline 2 & 6.47 & 6.75 & 6.39 & 6.73 & 6.55 \\
\hline 3 & - & - & - & - & - \\
\hline 4 & - & - & - & - & - \\
\hline 5 & 6.48 & 6.47 & 6.47 & 6.50 & 6.66 \\
\hline \multirow[t]{2}{*}{6} & 6.53 & 6.74 & 6.53 & 6.81 & 6.49 \\
\hline & 2.57 & 2.94 & 2.75 & 3.14 & 2.46 \\
\hline 7 & 2.37 & 2.46 & 2.19 & 2.64 & 2.30 \\
\hline 8 & 2.29 & 1.81 & 2.22 & 2.22 & 1.83 \\
\hline 9 & 5.06 & 4.99 & 5.03 & 5.00 & 4.90 \\
\hline 1a & - & - & - & - & - \\
\hline $2 a$ & 6.36 & 6.45 & 6.49 & 6.55 & 6.51 \\
\hline $3 a$ & - & - & - & - & - \\
\hline $4 a$ & - & - & - & - & - \\
\hline $5 a$ & 6.41 & 6.48 & 6.50 & 6.47 & 6.65 \\
\hline $6 a$ & 6.47 & 6.55 & 6.59 & 6.43 & 6.44 \\
\hline $7 \mathrm{a}$ & 2.68 & 2.55 & 2.60 & 2.97 & 2.39 \\
\hline $8 a$ & 2.20 & 2.62 & 3.22 & 2.26 & 1.94 \\
\hline \multirow[t]{2}{*}{$9 a$} & 3.79 & 3.55 & 3.82 & 3.95 & 3.97 \\
\hline & 3.82 & 3.87 & 3.66 & 3.69 & 3.47 \\
\hline $\mathrm{OCH}_{2} \mathrm{O}$ & 5.89 & 5.89 & 5.90 & 5.90 & 5.83 \\
\hline $\mathrm{OCH}_{2} \mathrm{O}$ & 5.93 & 5.92 & 5.93 & 5.91 & 5.83 \\
\hline MAD & 0.17 & 0.18 & 0.22 & 0.24 & - \\
\hline RMSD & 0.20 & 0.24 & 0.35 & 0.30 & - \\
\hline
\end{tabular}

$\delta$ : chemical shift values; MAE: mean absolute error; RMSD: root mean square deviation.

the isolated compound, based only on these ${ }^{13} \mathrm{C}$ NMR statistical parameters.

Table 3 shows the comparison of the simulated ${ }^{1} \mathrm{H}$ chemical shifts obtained for the four diastereoisomers of cubebin with experimental data. Once again, ${ }^{1} \mathrm{H}$ NMR MAE and RMSD values are similar and cannot discriminate between the possible diastereoisomers, although $\mathbf{1}$ and 2 show the lowest values. These results clearly indicate that using only data based on the ${ }^{13} \mathrm{C}$ and ${ }^{1} \mathrm{H}$ chemical shifts it is difficult to determine the relative configuration of cubebin. This could easily lead to misassignment if empirical methodologies are exclusively used to determine the stereochemistry of this potential biological lignan.

After the ${ }^{13} \mathrm{C}$ and ${ }^{1} \mathrm{H}$ NMR chemical shifts calculations, even with diastereoisomers 2 showing the lowest ${ }^{13} \mathrm{C}$ and ${ }^{1} \mathrm{H}$ NMR MAE and RMSD values, it is not possible to 
obtain a reliable discrimination between the possible diastereoisomers 1-4 (Figure 1). Trying to increase the reliability of the discrimination, we employed the DP4+ procedure, proposed by Sarotti and co-workers. ${ }^{18}$ The basic idea of this procedure is to compare the experimental NMR data with all possible simulated structures. Taking into account the differences in chemical shifts obtained between the simulated and experimental values, each possible structure is ranked after the application of a Student's $t$-test, based on statistical treatment. ${ }^{18}$ This method has been established to provide a more reliable assignment procedure, when comparing with the statistical parameters, ${ }^{18-20}$ such as the MAE and RMSD values listed in Tables 2 and 3. The DP4+ value obtained using both the ${ }^{13} \mathrm{C}$ and ${ }^{1} \mathrm{H}$ NMR data in the scaled form (all data, sDP4+) enabled the assignment of diastereoisomer 2 as the most likely one, in overall confidence level of $97.9 \%$, against $1.15,0.87$ and $0.08 \%$ for diastereoisomers $\mathbf{1}, \mathbf{3}$ and $\mathbf{4}$, respectively (see Figure 2).

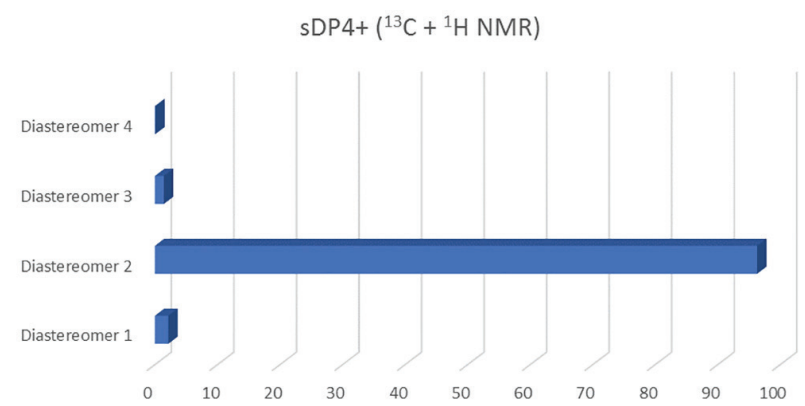

Figure 2. sDP4+ values (all data in the scaled form) obtained by correlating the calculated ${ }^{1} \mathrm{H}$ and ${ }^{13} \mathrm{C}$ NMR chemical shifts of the four diastereoisomers with the experimental NMR data of the isolated natural product.

For further verification of the reliability of this procedure, we also carried out X-ray diffraction study of the isolated cubebin. White single crystals suitable for X-ray diffraction analysis were obtained by slow evaporation of a cubebin acetone solution. Based on the $\mathrm{X}$-ray crystallographic analysis, the molecular structure was confirmed as the diastereoisomer 2 (Figure 1). Figure 3 shows the Oak Ridge thermal ellipsoid plot (ORTEP) diagram of the compound. Crystal data and refinements are provided in Table $\mathrm{S} 1$ of the Supplementary Information (SI) section.

Therefore, the relative stereochemical configuration of the isolated compound was unambiguously established as $\left(8 R^{*}, 8 \mathrm{a} R^{*}, 9 S^{*}\right)$ by the robust combination of $1 \mathrm{D}$ and 2D NMR studies, comparison of ${ }^{1} \mathrm{H}$ and ${ }^{13} \mathrm{C}$ NMR chemical shifts simulation, application of the sDP4+ method and $\mathrm{X}$-ray crystallography study. Next, using the proper relative configuration, we focused on the determination of

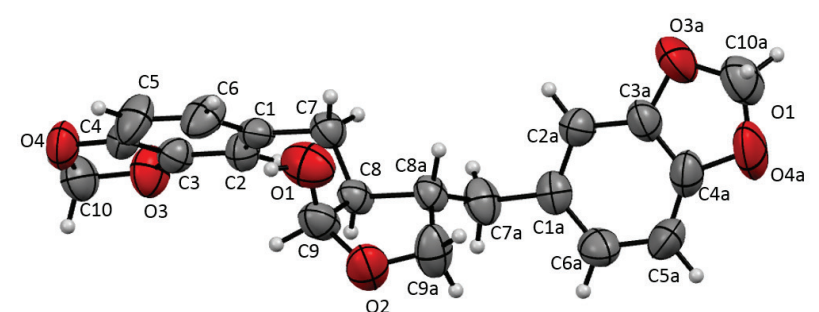

Figure 3. Asymmetric unit representation of dibenzylbutyrolactolic lignan. Displacement ellipsoids are drawn at the $50 \%$ probability level.

the $\mathrm{AC}$ of the isolated compound by means of chiroptical spectroscopy.

As mentioned in the context of ECD spectra, de Pascoli et al. ${ }^{9}$ reported that the ECD spectrum of different diastereoisomers of cubebin could display similar bands, directly related to the stereochemistry of the stereogenic centers C-8 and C-8a. ${ }^{9}$ Thus, any uncertainty about the relative configuration of the anomeric carbons can easily lead to incorrect stereochemistry assignment if only the empirical methodology is used, e.g., by just comparing the ECD spectrum obtained experimentally with those reported in the literature.Cases like these have already been seen in the literature ${ }^{21,22}$ and demand a more robust method to determine their relative configuration, preferentially by independent tools, including X-ray crystallography and NMR spectroscopy. ${ }^{17}$ Nevertheless, a combination of experimental and theoretical methods is highly recommended, to avoid errors in the stereochemical determination. ${ }^{17,21-25}$ Therefore, the use of ECD in this case is recommended to unambiguous and direct determination of the absolute stereochemistry, in combination with quantum chemical calculations and a high level of confidence in their relative configuration. ${ }^{17}$ It is noteworthy that this combined methodology has been deemed as one of the most powerful methodology for the stereochemical analysis of natural products and synthetic molecules. ${ }^{21-29}$ Thus, to unequivocal determination of the absolute stereochemistry of (-)-cubebin, we employed a combination of the experimental ECD spectrum with the corresponding one computed by quantum chemical methods.

The experimental ECD spectrum in the 190-300 nm (Figure 4) region measured in acetonitrile (ACN) clearly shows a negative Cotton effect at approximately $200 \mathrm{~nm}$, associated with the benzodioxole chromophore in cubebin. ${ }^{9}$

Figure 5 shows the comparison of the experimental ECD spectrum of isolated cubebin in $\mathrm{ACN}$ with the simulated data for the Boltzmann average of the 14 lowest-energy conformers identified for diastereoisomer $2(8 R, 8 \mathrm{a} R, 9 S)$ at the CAM-B3LYP/PCM(ACN)/TZVP (Coulombattenuating method Becke, 3-parameter, Lee-Yang-Parr/ polarizable continuum model(acetonitrile)/valence triplezeta polarization) level. Range-separated hybrid functional 


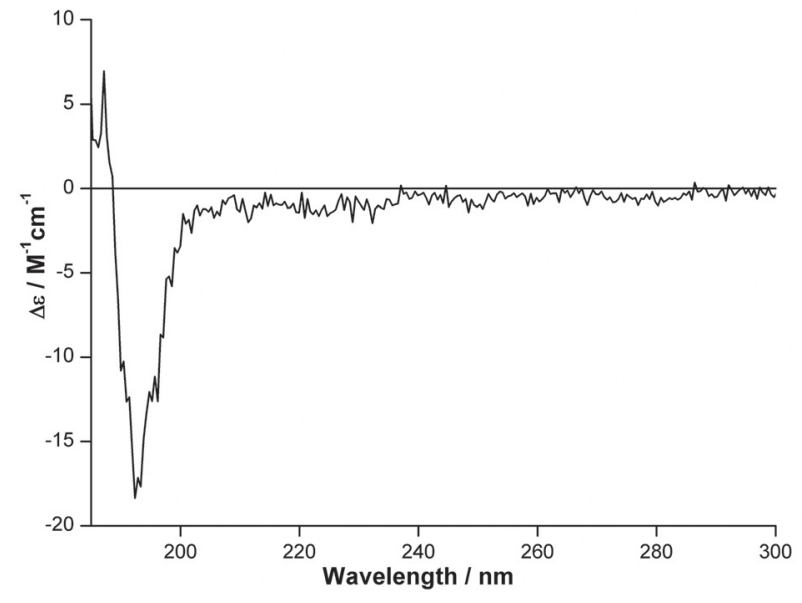

Figure 4. ECD spectrum of cubebin in acetonitrile (ACN).

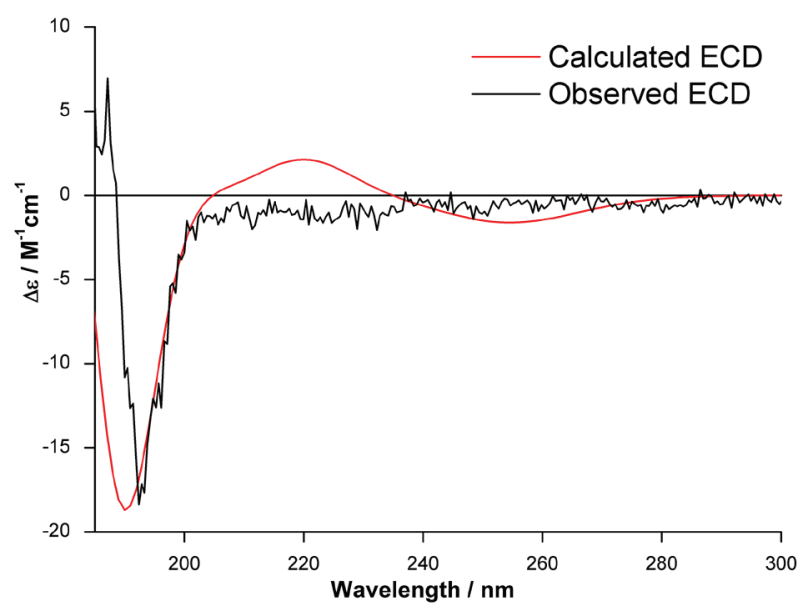

Figure 5. Comparison of the observed ECD spectrum of cubebin in ACN (black trace) with the calculated [CAM-B3LYP/PCM(ACN)/TZVP] ECD spectrum of the Boltzmann average of the 14 lowest-energy conformers identified for diastereoisomer $\mathbf{2}(8 R, 8 \mathrm{a} R, 9 S)$ of cubebin (red trace).

such as CAM-B3LYP, combined with the TZVP basis sets, were selected due to their good performance for ECD calculations..$^{29}$ The negative Cotton effect around $200 \mathrm{~nm}$ is perfectly reproduced in the calculations. The good agreement observed between the experimental and the time-dependent density functional theory (TDDFT) simulated spectrum allowed the unequivocal assignment of the absolute configuration of cubebin as $(8 R, 8 \mathrm{a} R, 9 S)$.

\section{Conclusions}

In conclusion, with the proper assignment of the relative configuration of (-)-cubebin, we described the first determination of its absolute configuration by the use of ECD, supported by quantum chemical calculations. The comparison of experimental ECD with the corresponding quantum chemical prediction of the correct diastereoisomer, confirmed by X-ray analysis and NMR studies, resulted in the definitive assignment of the $\mathrm{AC}$ of cubebin. When taken together, the analyses made here confirmed the $\mathrm{AC}$ of the naturally occurring (-)-cubebin as $(8 R, 8 \mathrm{a} R, 9 S)$.

\section{Experimental}

\section{General}

Solvents used for extraction and chromatography were acquired from Vetec ${ }^{\circledR}$ (Duque de Caxias, RJ, Brazil) and used without further purification. Acetonitrile used for ECD, dichloromethane for GC-MS and dimethyl sulfoxide (DMSO- $d_{6}$ ) were acquired from Sigma-Aldrich (São Paulo, Brazil). Silica gel used for vacuum liquid chromatography, flash chromatography and preparative thin layer chromatography were bought from Merck (Darmstadt, Germany).

\section{Plant material}

Piper cernuum Vell. was collected in January 2015 in Parque Nacional da Serra dos Órgãos, Guapimirim, RJ, Brazil (22 $29^{\prime} 36$ ”'S, $\left.42^{\circ} 59^{\prime} 54^{\prime \prime} \mathrm{W}\right)$ and identified by Dr Elsie Franklin Guimarães, a specialist in Piperaceae family. Voucher specimen was deposited in the Herbarium of the Botanical Garden Research Institute of Rio de Janeiro under the number RB457067.

\section{Extraction and isolation}

Dried and pulverized leaves of P. cernuum $(600 \mathrm{~g})$ were extracted by static maceration in methanol and concentrated under reduced pressure on rotary evaporator. The methanolic extract ( $80 \mathrm{~g}$ ) was re-suspended in mixture of $\mathrm{MeOH}: \mathrm{H}_{2} \mathrm{O}$ (7:3) and successively extracted with $n$-hexane, dichloromethane, ethyl acetate and $n$-butanol. Aiming at the isolation of cubebin, the dichloromethane fraction (15 g) was submitted to a vacuum liquid column chromatography (silica gel 60, 2-25 $\mu \mathrm{m}$ ) using a polarity gradient with small changes in the mobile phase composition with different mixtures of hexane:ethyl acetate (99:1-0:1, 11 fractions), ethyl acetate:methanol (9:1-0:1, four fractions) and methanol:water (8:2 and 6:4, two fractions), yielding 17 fractions. Fraction 9 (1.219 g) was eluted in normal phase flash column chromatography (silica gel 60, 230-400 mesh) with a gradient of polarity that changed from hexane:ethyl acetate to methanol, yielding 26 fractions. Fraction $3(255 \mathrm{mg})$ was subjected to reverse phase flash column chromatography (octadecylfunctionalized silica gel 60, 200-400 mesh) eluted in different proportions of methanol:water (6:4 and 8:2, five fractions each), methanol:dicloromethane (2:8 
and 8:2, five fractions each) and dichloromethane (one fraction), affording 21 fractions. Fractions 8 and 9 were combined $(89 \mathrm{mg}$ ) and subjected to preparative layer plate chromatography (silica gel $60 \mathrm{GF}_{254}, 2-25 \mu \mathrm{m}$ ), eluted with dichloromethane:methanol (95:5) and observed under $254 \mathrm{~nm}$ UV light to afford cubebin $(27 \mathrm{mg})$. The basic structure of cubebin was confirmed by GC-MS and comparison of its ${ }^{1} \mathrm{H}$ and ${ }^{13} \mathrm{C}$ NMR spectra with the published data by de Pascoli et al. ${ }^{9}$ For the X-ray analysis, the amorphous powder was subjected to the crystallization: the powder was solubilized with acetone followed by addition of hexane until turbidity. The sample was dried at room temperature, furnishing the cubebin crystals.

\section{GC-MS analysis}

GC-MS analysis of cubebin was performed using a Hewlett-Packard 6890 GC coupled to a Hewlett-Packard 5972 MS equipped with a DB-5MS (5\% diphenyl/95\% dimethyl polysiloxane) fused silica capillary column $(30 \mathrm{~m} \times 0.25 \mu \mathrm{m}$ ID (inner diameter) $\times 0.25 \mu \mathrm{m} \mathrm{df}($ film thickness)). For GC-MS detection, an electron ionization system was operated in electron impact mode with an ionization energy of $70 \mathrm{eV}$. Helium gas $(99.999 \%)$ was used as a carrier gas at a constant flow rate of $0.5 \mathrm{~mL} \mathrm{~min}^{-1}$. The solvent delay was 0 to $3.5 \mathrm{~min}$, and the total GC-MS running time was $60 \mathrm{~min}$. The injector temperature was maintained at $270{ }^{\circ} \mathrm{C}$, the ion-source temperature was $250^{\circ} \mathrm{C}$ and the oven temperature was programmed from $70{ }^{\circ} \mathrm{C}$, with an increase of $4{ }^{\circ} \mathrm{C} \mathrm{min}^{-1}$ to $315^{\circ} \mathrm{C}$. Mass spectra were taken at $70 \mathrm{eV}$; a scan interval of $0.5 \mathrm{~s}$ and fragments from 40 to $700 \mathrm{Da}$. Data acquisition and handling were done via ChemStation software. ${ }^{30}$

\section{NMR analysis}

The NMR spectra were obtained on a Varian VNMRS $500 \mathrm{MHz}$, operating at $500 \mathrm{MHz}$ for ${ }^{1} \mathrm{H}$ and $125 \mathrm{MHz}$ for ${ }^{13} \mathrm{C}$ frequencies, with tetramethylsilane (TMS) as the internal standard. Dimethyl sulfoxide- $d_{6}$ was chosen as solvent to ensure good solubility of the sample.

\section{Electronic circular dichroism}

ECD spectrum was obtained for solutions $\left(1 \mathrm{mg} \mathrm{mL}^{-1}\right)$ in ACN on a Chirascan (Applied Photophysics Ltd., UK) in the $190-350 \mathrm{~nm}$ region in a $0.1 \mathrm{~cm}$ path length cell and a bandwidth of $1 \mathrm{~nm}$ at room temperature. The reported $\Delta \varepsilon$ (differential molar absorptivity) values are expressed in units of $\mathrm{L} \mathrm{mol}^{-1} \mathrm{~cm}^{-1}$. Acetonitrile was chosen as solvent for the preparation of the sample due to its cutoff wavelength value of $190 \mathrm{~nm}$, below which the solvent absorption becomes excessive.

\section{Specific rotation}

The optical rotations at $589 \mathrm{~nm}$ were measured for solutions $\left(0.5 \mathrm{mg} \mathrm{mL}^{-1}\right)$ in ACN on a Jasco P-200 polarimeter (Jasco Brasil, São Paulo, Brazil), at $25^{\circ} \mathrm{C}$, using a $2.5 \mathrm{~mm}$ cell. Specific rotation $[\alpha]_{25}^{\mathrm{D}}:-83^{\circ}$.

\section{Calculations}

Randomized conformational searches were performed for each of the four possible diastereoisomers of cubebin (Figure 1), using the Monte Carlo method and MMFF force field in the Spartan'10 software package. ${ }^{31}$ The more stable conformations, within a $10.0 \mathrm{kcal} \mathrm{mol}^{-1}$ energy range, were reoptimized using the mPW1PW91/6-31G* DFT method. The resulting conformers within the energy range of $2.5 \mathrm{kcal} \mathrm{mol}^{-1}$, accounting for more than $99.0 \%$ of the total Boltzmann population, were then used for NMR and ECD calculations. This theoretical approach computes NMR chemical shifts with high accuracy and low computational cost, being considered one of high accuracy methods available. ${ }^{32}$ For each selected structure, ${ }^{13} \mathrm{C}$ and ${ }^{1} \mathrm{H}$ NMR chemical shifts were calculated using the GIAO-mPW1PW91/6-31G(d)// mPW1PW91/6-31G(d) DFT approach. The Gaussian 09 software package ${ }^{33}$ was used. Calculated chemical shifts were scaled using a linear equation $\left(\delta_{\text {scal }}=1.05 \delta_{\text {calc }}-1.22\right) .{ }^{32}$ This approach allows the cancellation of systematic errors as scaling factors are determined via linear regression analyses between the calculated and experimental chemical shifts of a pool of adequately chosen compounds. This is a good alternative to avoid more demanding calculations necessary to include solvent and rovibration effects. ${ }^{32}$ To apply the DP4+ parameter, it was used the Excel spreadsheet provided by the authors. ${ }^{18}$

After assignment of the relative configuration, the correct diastereoisomer were reoptimized at B3LYP/6-31G(d) and used for simulation of the ECD spectrum with CAM-B3LYP/TZVP//B3LYP/6-31G(d) TD-DFT approach, using the PCM solvent (ACN) method, in order to take into account solvation effects (see SI section). The final ECD spectra were generated according to Boltzmann weighting of the lowest-energy conformers identified and plotted using Origin 8 software. ${ }^{34}$

\section{X-ray data collection and structure refinement}

X-ray diffraction data for cubebin was carried out with 
radiation Mo Ka $(\lambda=0.71073 \AA)$ in Bruker D8 Venture diffractometer. ${ }^{35}$ Using Olex $2,{ }^{36}$ the structure was solved with the olex2.solve ${ }^{37}$ structure solution program using Charge Flipping and refined with the ShelXL ${ }^{38}$ refinement package using least squares minimization. All $\mathrm{H}$ atoms were refined with fixed individual displacement parameters $\left[\mathrm{U}_{\text {iso }} /(\mathrm{H})=1.2 \mathrm{Ueq}\left(\mathrm{Csp}^{2}\right.\right.$ and $\left.\mathrm{C}_{\text {ar }}\right)$ or $\left.1.5 \mathrm{U}_{\text {eq }}\left(\mathrm{Csp}^{3}\right)\right]$ using a riding model. All non-hydrogen atoms were refined anisotropically. Molecular graphics were drawn using ORTEP-3 for Mercury. ${ }^{39}$

\section{Legal information}

The sample collection of $P$. cernuum was authorized by the Chico Mendes Institute of Biology (ICMBio) through the Biodiversity authorization and information system (SISBio) in document number 45566-1. Access was authorized by the Management Board of Genetic Heritage Council in process number 010771/ 2014-0.

\section{Supplementary Information}

Crystallographic data (excluding structure factors) for the structures in this work were deposited in the Cambridge Crystallographic Data Centre as supplementary publication number CCDC 1991277. Copies of the data can be obtained, free of charge, via https://www.ccdc.cam. ac.uk/structures/. Crystallographic data is also available for download in CIF format at http://jbcs.sbq.org.br.

Supplementary information is available free of charge at http://jbcs.sbq.org.br as PDF file.

\section{Acknowledgments}

The authors thank LDRX-UFF (www.ldrx.uff.br/) for the X-ray diffraction analysis and for the facilities. We wish to thank CNPq, and FAPERJ (grant 211.319-2019), for financial support. This study was financed in part by the Coordenação de Aperfeiçoamento de Pessoal de Nível Superior, Brazil (CAPES), finance code 001. We dedicate this paper to memory of Professor Mauro Barbosa de Amorim (1954-2019), a masterful teacher and mentor, and more than that, a father, a husband and a friend.

\section{Author Contributions}

Alessandra L. Valverde, Davyson L. Moreira, Thatyana R. A. Vasconcelos, Fernando M. dos Santos Junior, and Arthur L. Macedo designed the experiments; Arthur L. Macedo, Lucas H. Martorano and Ana Carolina F. de Albuquerque executed the experimental part; Vinicius R.
Campos executed the X-ray part; José W. M. Carneiro, Rodolfo G. Fiorot, Ana Carolina F. de Albuquerque and Fernando M. dos Santos Junior executed the calculations; Fernando M. dos Santos Junior and Arthur L. Macedo wrote the manuscript with the contributions of all authors. Alessandra L. Valverde, Davyson L. Moreira, Thatyana R. A. Vasconcelos, Fernando M. dos Santos Junior, José W. M. Carneiro, Vinicius R. Campos and all other authors critically reviewed and approved the manuscript.

\section{References}

1. Pan, J. Y.; Chen, S. L.; Yang, M. H.; Wu, J.; Sinkkonen, J.; Zou, K.; Nat. Prod. Rep. 2009, 26, 1251.

2. Pissurno, A. P. R.; Laurentiz, R. S.; Rev. Virtual Quim. 2017, 9, 2.

3. Macedo, A. L.; da Silva, D. P. D.; Moreira, D. L.; de Queiroz, L. N.; Vasconcelos, T. R. A.; Araujo, G. F.; Kaplan, M. A. C.; Pereira, S. S. C.; de Almeida, E. C. P.; Valverde, A. L.; Robbs, B. K.; Biomed. Pharmacother. 2019, 110, 342.

4. Umezawa, T.; Okunishi, T.; Shimada, M.; Wood Res., Bull. Wood Res. Inst., Kyoto Univ. 1997, 84, 62.

5. Umezawa, T.; Phytochemistry Rev. 2003, 2, 371.

6. da Silva, R.; de Souza, G. H.; da Silva, A. A.; de Souza, V. A.; Pereira, A. C.; Royo, V.; Silva, M. L.; Donate, P. M.; de Matos, A. L.; Carvalho, J. C.; Bastos, J. K.; Bioorg. Med. Chem. Lett. 2005, 15, 1033.

7. Zhang, J.; Chen, J.; Liang, Z.; Zhao, C.; Chem. Biodivers. 2014, 11,1 .

8. Marcotullio, M. C.; Pelosi, A.; Curini, M.; Molecules 2014, 19, 14862.

9. de Pascoli, I. C.; Nascimento, I. R.; Lopes, L. M. X.; Phytochemistry 2006, 67, 735.

10. Li, N.; Wu, J. L.; Sakai, J.; Ando, M.; J. Nat. Prod. 2003, 66, 1421.

11. Barrero, A. F.; Haïdour, A.; Muñoz Dorado, M.; Grávalos, D. G.; Quesada, T. G.; J. Nat. Prod. 1994, 57, 713.

12. Gozler, B.; Rentsch, D.; Gozler, T.; Unver, N.; Hesse, M.; Phytochemistry 1996, 42, 695.

13. Polavarapu, P. L.; Chem. Rec. 2007, 7, 125.

14. Petrovic, A. G.; Navarro-Vázquez, A.; Alonso-Gómez, J. L.; Curr. Org. Chem. 2010, 14, 1612.

15. Batista, A. N. L.; dos Santos, F. M. J.; Batista, J. M. J.; Cass, Q. B.; Molecules 2018, 23, 492.

16. Batista, J. M. J.; Blanch, E. W.; Bolsani, S.; Nat. Prod. Rep. 2015, 32, 1280.

17. Pescitelli, G.; Bruhn, T.; Chirality 2016, 28, 466.

18. Grimblat, N.; Zanardi, M. M.; Sarotti, A. M.; J. Org. Chem. 2015, 80, 12526; sarotti-NMR.weebly.com, accessed in May 2020.

19. Zanardi, M. M.; Suárez, A. G.; Sarotti, A. M.; J. Org. Chem. 2017, 82, 1873. 
20. Sarotti, A. M.; Org. Biomol. Chem. 2018, 16, 944.

21. Junior, F. M.; Velozo, L. S.; de Carvalho, E. M.; Marques, A. M.; Borges, R. M.; Trindade, A. P.; dos Santos, M. I.; de Albuquerque, A. C.; Costa, F. L.; Kaplan, M. A.; de Amorim, M. B.; Molecules 2013, 18, 13520.

22. Junior, F. M. S.; Covington, C. L.; de Amorim, M. B.; Velozo, L. S. M.; Kaplan, M. A. C.; Polavarapu, P. L.; J. Nat. Prod. 2014, 77, 1881.

23. Junior, F. M. S.; Covington, C. L.; de Albuquerque, A. C. F.; Lobo, J. F. R.; Borges, R. M.; de Amorim, M. B.; Polavarapu, P. L.; J. Nat. Prod. 2015, 78, 2617.

24. dos Santos Jr., F. M.; Bicalho, K. U.; Calisto, I. H.; Scatena, G. S.; Fernandes, J. B.; Cass, Q. B.; Batista Jr., J. M.; Org. Biomol. Chem. 2018, 16, 4509.

25. Batista, N. L. A.; dos Santos Jr., F. M.; Valverde, A. L.; Batista Jr., J. M.; Org. Biomol. Chem. 2019, 17, 9772.

26. Gimenes, L.; Batista Jr., J. M.; dos Santos Jr., F. M.; da Silva, S. M.; Luna-Dulcey, L.; Ellena, J.; Cominetti, M. R.; Silva, F. G. F.; Viera, P. C.; Fernandes, J. B.; Staerk, D.; Phytochemistry 2019, 163, 38.

27. Amorim, M. R.; Hilário, F.; Junior, F. M. S.; Batista, J. M.; Bauab, T. M.; Araújo, A. R.; Carlos, I. Z.; Vilegas, W.; dos Santos, L. C.; Planta Med. 2019, 85, 957.

28. Covington, C. L.; Junior, F. M. S.; Silva, J. H. S.; Kuster, R. M.; de Amorim, M. B.; Polavarapu, P. L.; J. Nat. Prod. 2016, 79,530 .

29. Jimenez, D. E. Q.; Barreiro, J. C.; dos Santos Jr., F. M.; de Vasconcellos, S. P.; Porto, A. L. M.; Batista Jr., J. M.; Chirality 2019, 31, 534.

30. GC/MSD ChemStation Software; Agilent, Santa Clara, CA, USA, 2005.

31. Spartan; Wavefunction, Irvine, CA, USA, 2014.

32. Costa, F. L. P.; de Albuquerque, A. C. F.; Borges, R. M.; Junior, F. M. S.; de Amorim, M. B.; J. Comput. Theor. Nanosci. 2014, $11,219$.
33. Frisch, M. J.; Trucks, G. W.; Schlegel, H. B.; Scuseria, G. E.; Robb, M. A.; Cheeseman, J. R.; Scalmani, G.; Barone, V.; Mennucci, B.; Petersson, G. A.; Nakatsuji, H.; Caricato, M.; Li, X.; Hratchian, H. P.; Izmaylov, A. F.; Bloino, J.; Zheng, G.; Sonnenberg, J. L.; Hada, M.; Ehara, M.; Toyota, K.; Fukuda, R.; Hasegawa, J.; Ishida, M.; Nakajima, T.; Honda, Y.; Kitao, O.; Nakai, H.; Vreven, T.; Montgomery Jr., J. A.; Peralta, J. E.; Ogliaro, F.; Bearpark, M.; Heyd, J. J.; Brothers, E.; Kudin, K. N.; Staroverov, V. N.; Kobayashi, R.; Normand, J.; Raghavachari, K.; Rendell, A.; Burant, J. C.; Iyengar, S. S.; Tomasi, J.; Cossi, M.; Rega, N.; Millam, N. J.; Klene, M.; Knox, J. E.; Cross, J. B.; Bakken, V.; Adamo, C.; Jaramillo, J.; Gomperts, R.; Stratmann, R. E.; Yazyev, O.; Austin, A. J.; Cammi, R.; Pomelli, C.; Ochterski, J. W.; Martin, R. L.; Morokuma, K.; Zakrzewski, V. G.; Voth, G. A.; Salvador, P.; Dannenberg, J. J.; Dapprich, S.; Daniels, A. D.; Farkas, Ö.; Foresman, J. B.; Ortiz, J. V.; Cioslowski, J.; Fox, D. J.; Gaussian 09, Revision A.01; Gaussian, Inc., Wallingford, CT, USA, 2009.

34. OriginPro 8, v. 80724; OriginLab Corporation, Northampton, MA, USA, 2020.

35. Bruker APEX3, SAINT and SADABS; Bruker AXS Inc., Madison, Wisconsin, USA, 2016.

36. Dolomanov, O. V.; Bourhis, L. J.; Gildea, R. J.; Howard, J. A. K.; Puschmann, H.; J. Appl. Crystallogr. 2009, 42, 339.

37. Bourhis, L. J.; Dolomanov, O. V.; Gildea, R. J.; Howard, J. A. K.; Puschmann, H.; Acta Crystallogr. 2015, A71, 59.

38. Sheldrick, G. M.; Acta Crystallogr. 2015, C71, 3.

39. Macrae, C. F.; Edgington, P. R.; McCabe, P.; Pidcock, E.; Shields, G. P.; Taylor, R.; Towler, M.; van de Streek, J.; J. Appl. Crystallogr. 2006, 39, 453.

Submitted: March 18, 2020 Published online: May 29, 2020 